\title{
PREPARATION OF ASPERGILLUS FUMIGATUS ANTIGENS AND THEIR ANALYSIS BY TWO-DIMENSIONAL IMMUNOELECTROPHORESIS
}

\author{
Veronica M. Hearn, Elaine V. Wilson, A. G. Proctor and D. W. R. \\ MACKENZIE
}

Mycological Reference Laboratory, London School of Hygiene and Tropical Medicine, Keppel Street, Gower Street, London WCIE 7 HT

\section{Plates XXV-XXIX}

SEROLOGY is widely used in the study of the involvement of Aspergillus spp. in a variety of pulmonary diseases. Since the introduction of double-diffusion and electrophoretic techniques in agar, soluble antigens have been obtained in one or other of the following ways. A culture is grown for 4-6 weeks and the supernatant fluid is used as a source of antigens (Longbottom and Pepys, 1964). A variant of this is the addition of toluene to a young culture, causing autolysis in 2-3 days (Pappagianis et al., 1961). Another method is the mechanical disruption of young mycelium approximately 3 days old, at the end of the logarithmic phase of growth (Wada, 1960; Azuma et al., 1967; Tran van Ky, Biguet and Vaucelle, 1968; Bardana et al., 1972; Kim and Chaparas, 1978; Hearn and Mackenzie, 1979); this last method has been used here in a search for more specific and reproducible antigens and to investigate the role and the relative immunological importance of the different antigens in the invaded host.

Ammonium sulphate (AS) precipitation has been used previously to fractionate the culture-filtrate antigens of $A$. fumigatus (Longbottom, 1964) and two-dimensional immunoelectrophoresis can be used to assess antigenic variation and individual IgG antibody response (Longbottom, 1978). The method has been used here to study the distribution of mycelial antigens precipitable by increasing concentrations of AS and to determine their reactivity against test sera. Two different batches of antigen have been analysed by the use of a serum raised against culture-filtrate antigens and a selected human serum. With selected antigenic preparations the IgG-antibody variation in individual sera has been examined; concurrently the detection of some recurring antigenantibody interactions has been made possible. Finally, the procedure has proved useful for studies on the chemical nature of the antigens, by lectin-binding with concanavalin $\mathrm{A}$.

\section{MATERIALS AND METHODS}

Preparation of antigenic fractions. A water-soluble extract from 3-day-old mycelium of $A$. 
fumigatus (strain NCPF2109) was prepared as described by Proctor (1976). Two methods were used for salt precipitation. The first involved increasing concentrations of ammonium sulphate up to $75 \%$ saturation; four fractions were collected from batch I of $A$. fumigatus, i.e., $0-30 \%$ AS (w/v), 30-50\% AS, 50-75\% AS, and the soluble supernate (designated fractions $1-4$, respectively). In the second procedure, four fractions were again collected, from batch II of $A$. fumigatus, over the following range: $0-15 \%$ AS, $15-30 \%$ AS, $30-50 \%$ AS and the $50 \%$ AS supernate, designated fractions $1 \mathrm{a}-4 \mathrm{a}$, respectively. The precipitation was done overnight at $4^{\circ} \mathrm{C}$; precipitates were collected by centrifugation and dissolved in the minimum volume of distilled water. All fractions, including supernates, were exhaustively dialysed against water and insoluble residue was spun off. The soluble supernates were concentrated to a suitable volume in polyethylene glycol of mol. wt. 6000 . Fractions were stored at $-20^{\circ} \mathrm{C}$.

Production of antiserum. The unfractionated water-soluble extract at $60 \mathrm{mg}$ dry weight $/ \mathrm{ml}$ was mixed with an equal volume of Freund's incomplete adjuvant and injected subcutaneously into New Zealand white rabbits, in 1-ml portions at weekly intervals for 5-6 weeks. The serum was used unconcentrated.

Hyperimmune serum was raised in rabbits to the culture-filtrate antigens of $A$. fumigatus. The serum was a gift from Dr K. Holmberg of the State Bacteriology Laboratory, Stockholm, and was used unconcentrated.

Human antiserum. Serum samples were from 10 patients suffering from allergic bronchopulmonary aspergillosis (ABPA) or aspergilloma. Some were specimens submitted to our laboratory while the others were kindly provided by Dr J. Edwards of the MRC Pneumoconiosis Unit, Llandough Hospital, Penarth, S. Glam. Sera from patients with aspergilloma were used unconcentrated.

Concentration of patients' sera. The bulk of the plasma proteins were precipitated with caprylic acid (Steinbuch and Audran, 1969). The IgG component, and a portion of the IgA of the supernate were concentrated fivefold with polyethylene glycol in $0.9 \%$ saline at $4{ }^{\circ} \mathrm{C}$. This procedure was carried out on selected sera from patients with ABPA.

Two-dimensianal immunoelectrophoresis. Tests were done on $8.2 \times 7.6-\mathrm{cm}$ slides in a $1.2-\mathrm{mm}$ layer of tris-barbitone buffered agarose gel ( $1 \%$ HSA Litex from Litex, Denmark) at $p \mathrm{H} 8.6$ (Bøg-Hansen and Brogren, 1974). The antigen well was cut to hold 7-25 $\mu \mathrm{l}$ of solution at the cathodic end of the plate. Sometimes the well was placed midway between the two poles to check for the presence of cathodic components in the antigenic mixture. In line with this well and $4 \mathrm{~mm}$ (edge-to-edge) in front was placed another well to hold $5 \mu \mathrm{l}$ of a reference albumin antigen. In the second dimension, the separated antigenic moieties were electrophoresed into a window containing agarose mixed with the test antiserum (Longbottom, 1978) and with the antialbumin serum. The sera were used at the following levels: anti-bovine albumin (MilesYeda Ltd, Rehevak, Israel) at $2 \mu \mathrm{l} / \mathrm{cm}^{2}$; homologous and culture-filtrate antisera at $8 \mu \mathrm{l} / \mathrm{cm}^{2}$; aspergilloma antisera at $12 \mu \mathrm{l} / \mathrm{cm}^{2}$; ABPA concentrated sera at $16 \mu \mathrm{l} / \mathrm{cm}^{2}$. In figs. 3-8, the most intensely stained discrete peak with highest anodic mobility is the albumin/anti-albumin reference system. For tandem electrophoresis, the albumin was replaced by the relevant antigenic fraction. An intermediate gel of $1.5 \mathrm{~cm}$ was used in the lectin-binding experiments; $1 \% \mathrm{HSB}$ Litex (low electroendosmosis) was substituted for HSA Litex. Electrophoresis at room temperature was done in the first dimension at $10 \mathrm{~V} / \mathrm{cm}$ for approximately $45 \mathrm{~min}$.; in the second dimension the potential difference was $1.5 \mathrm{~V} / \mathrm{cm}$, applied overnight. Antigen preparations were used at the following protein concentrations: $40-50 \mu \mathrm{g} /$ test except for the supernates which were examined at $50 \mu \mathrm{g}$ and $100 \mu \mathrm{g} /$ test. In all procedures the slides were washed, dried and stained with $0.5 \%$ Coomassie Brilliant Blue R, No 42660 (Raymond Lamb, Sunbeam Rd., London NW10 6JL). The peaks of antibody-antigen precipitates were numbered 1, 2, etc. beginning with that of highest anodic mobility and closest to the albumin reference standard.

Lectin-binding experiments. Concanavalin A (A grade: Calbiochem, California, USA) was used at a concentration of $1 \mathrm{mg}$ dry weight $/ \mathrm{ml}$ of intermediate gel solution. This gel was poured at the end of electrophoresis in the first dimension; when set, the upper portion of the gel containing the antiserum was poured.

Double-diffusion tests were by the method of Fletcher, Rondle and Murray (1970), in Oxoid Agar $1 \%(\mathrm{w} / \mathrm{v})$ in a borate buffer at $\mathrm{pH} 8.2$ containing EDTA $0.5 \%$. Antigenic preparations 
were used at protein concentrations of $15 \mathrm{mg} / \mathrm{ml}$ (fraction 1), $20 \mathrm{mg} / \mathrm{ml}$ (fraction 2) and $8 \mathrm{mg} / \mathrm{ml}$ (fractions 3 and 4).

Polyacrylamide-gel electrophoresis (PAGE) was done essentially as described by Lund (1965) with a $7 \cdot 5 \%$ separating gel. Amounts of antigen applied to the gels were: fraction 1a, 0.85 mg protein; fractions $2 \mathrm{a}$ and $3 \mathrm{a}, 1.25 \mathrm{mg}$ protein; fraction $2,2.2 \mathrm{mg}$ protein. After electrophoresis the gels were bisected longitudinally, one half of each was fixed in trichloroacetic acid $10 \%$ $(\mathrm{w} / \mathrm{v})$ and stained with Coomassie Brilliant Blue R. The other half of each gel was embedded in $25 \mathrm{ml}$ of Oxoid Agar No. $11 \%(\mathrm{w} / \mathrm{v})$ in a $10 \times 10-\mathrm{cm}$ plastic dish. These dishes were kept at room temperature for $c .4 \frac{1}{2} \mathrm{~h}$ to allow diffusion of antigens from the gels. Troughs $2 \mathrm{~mm} \times 6 \mathrm{~cm}$ were then made with a Shandon Cutter (Shandon Scientific Co. Ltd, Pound Lane, London) 8-9 mm from the edge of the embedded gel and filled with $250 \mu \mathrm{l}$ of the appropriate antiserum. Incubation was allowed to proceed for 6 days at room temperature. The gel layer was covered with a staining solution of $0.05 \%$ Coomassie Blue (in a mixture of glacial acetic acid $10 \% \mathrm{v} / \mathrm{v}$ and isopropanol $10 \% \mathrm{v} / \mathrm{v}$ ) for $1 \mathrm{~h}$ and then destained in acetic acid $10 \%$. For unstirred destaining, a period of 4 days was required with several changes of acid wash.

Chemical Analysis. Total neutral sugars were estimated as described by Dubois et al., (1956). Protein was measured with the Folin-Ciocalteau reagent with bovine serum albumin as a standard (Lowry et al., 1951).

\section{RESULTS \\ Chemical analysis}

The total protein and neutral polysaccharide obtained from the aqueous extract of $A$. fumigatus by a one-step precipitation with $75 \%$ ammonium sulphate was $46 \% \pm 7 \%$ (designated the control precipitate). By fractional precipitation, four samples were prepared; the analytical and serological data are summarised in the table. The protein: carbohydrate ratios (adjusted to the base of 1) ranged from $1 \cdot 4: 1$ for fraction 1 , to $1 \cdot 2: 1$ for fraction 2 , to $0 \cdot 5: 1$ for fraction 3 , and $0.07: 1$ for fraction 4 . Thus the first fractions contained a higher proportion of protein than the later fractions which had become carbohydrate enriched. The smallest amount of material recovered was in fraction 3, giving insufficient material for analysis by PAGE. Fractions 1 and 2 contained several components distributed throughout the gel that were detectable with a protein stain, but few components were visible in fraction 4 . This fraction was also the least reactive on double diffusion.

TABLE

Composition of ammonium sulphate precipitated fractions from mycelial extracts of Aspergillus fumigatus

\begin{tabular}{c|cccc}
\hline $\begin{array}{c}\text { Fraction } \\
\text { no.* }\end{array}$ & $\begin{array}{c}\text { Protein: } \\
\text { carbohydrate ratio } \dagger\end{array}$ & $\begin{array}{c}\text { Percentage } \\
\text { yield } \ddagger\end{array}$ & $\begin{array}{c}\text { Number of } \\
\text { PAGE bands } \S\end{array}$ & $\begin{array}{c}\text { Number of } \\
\text { DD lines }\end{array}$ \\
\hline 1 & $8 \cdot 6: 6 \cdot 3$ & $14 \cdot 5$ & $10-12$ & 4 \\
2 & $19 \cdot 6: 15 \cdot 7$ & $17 \cdot 4$ & 20 & 4 \\
3 & $1 \cdot 4: 2 \cdot 8$ & $6 \cdot 2$ & ND & 4 \\
4 & $1 \cdot 8: 24 \cdot 3$ & $13 \cdot 8$ & 4 & 1 \\
\hline
\end{tabular}

PAGE = polyacrylamide-gel electrophoresis; $\mathrm{DD}=$ double diffusion; $\mathrm{ND}=$ not determined.

* See text for definition of the fractions.

$\dagger$ Shown as total protein: neutral polysaccharide $(\mathrm{mg})$ in $154 \mathrm{mg}$ of unfractionated water-soluble material.

$\ddagger$ The sum of the sum of the protein and polysaccharide yielded by each fraction

$\S$ Detectable with Coomassie Blue when $1 \mathrm{mg}$ of protein was applied to each gel. 


\section{PAGE-immunodiffusion}

Ammonium sulphate fractions, after separation by PAGE, were allowed to diffuse against a variety of test sera. Precipitation arcs were distributed along the length of the gels; only fractions 1a-3a and fractions 1 and 2 , were tested (figs. 1 and 2). Precipitation arcs in the middle region were more pronounced with human than with rabbit sera. The small-molecular-weight constituents with high anodal mobilities were very reactive in all systems tested. Fraction la, though showing mainly trace bands on PAGE (protein:carbohydrate ratio $=0.33: 1$ ), gave a picture very similar to that of fraction 2 , in which many components were readily detectable.

\section{Ammonium sulphate fractions tested by immunoelectrophoresis}

Initially, fractions $1-4$ and the control precipitate preparation of $A$. fumigatus batch I were analysed by immunoelectrophoresis against the hyperimmune antiserum to culture-filtrate antigens. The bulk of the precipitin activity was found in fractions 1 and $2(0-50 \%$ AS precipitates), when compared with the control precipitate. The AS-soluble material (fraction 4), like fraction 3, showed only one or two readily identifiable precipitation peaks with mobilities midway between the origin and the albumin reference standard. Fraction 4 from two batches, when tested for cathodic components, was found to give one intensely staining precipitation arc below the window, presumably due to electroendosmosis of serum immunoglobulins. Of nine sera tested, three contained antibodies to this antigen which was used at $25 \mathrm{mg}$ of polysaccharide/ml. For this reason, even with positive sera, this component could not be detected in an unfractionated antigenic preparation.

\section{Ammonium sulphate fractions tested with human sera}

At this stage, a narrower range $(0-50 \%)$ of AS-precipitable material from another preparation of $A$. fumigatus (batch II) was studied. It was subdivided into three fractions, 1a-3a, and the resultant supernate (fraction 4a). Antigenic distribution was examined with hyperimmune serum; at the same time, batch variability was assessed on the AS and control preparations (figs. 3a and $3 b)$. All fractions were then tested against unconcentrated serum from patients with aspergilloma and against concentrated ABPA serum. Similar results were obtained with hyperimmune serum and both types of patient's sera; a greater number of antigen-antibody precipitates were seen (figs. $4 \mathrm{a}$ and $4 \mathrm{~b})$ in the first two fractions ( $0-30 \%$ AS precipitates). More weakly reactive components were detected when fraction 3a was tested against sera from patients with ABPA and aspergilloma while the $50 \%$ AS-soluble supernatant showed little reactivity against either type of antiserum.

\section{Antigenic distribution}

The presence of common antigens in 1a-3a AS fractions was determined by 

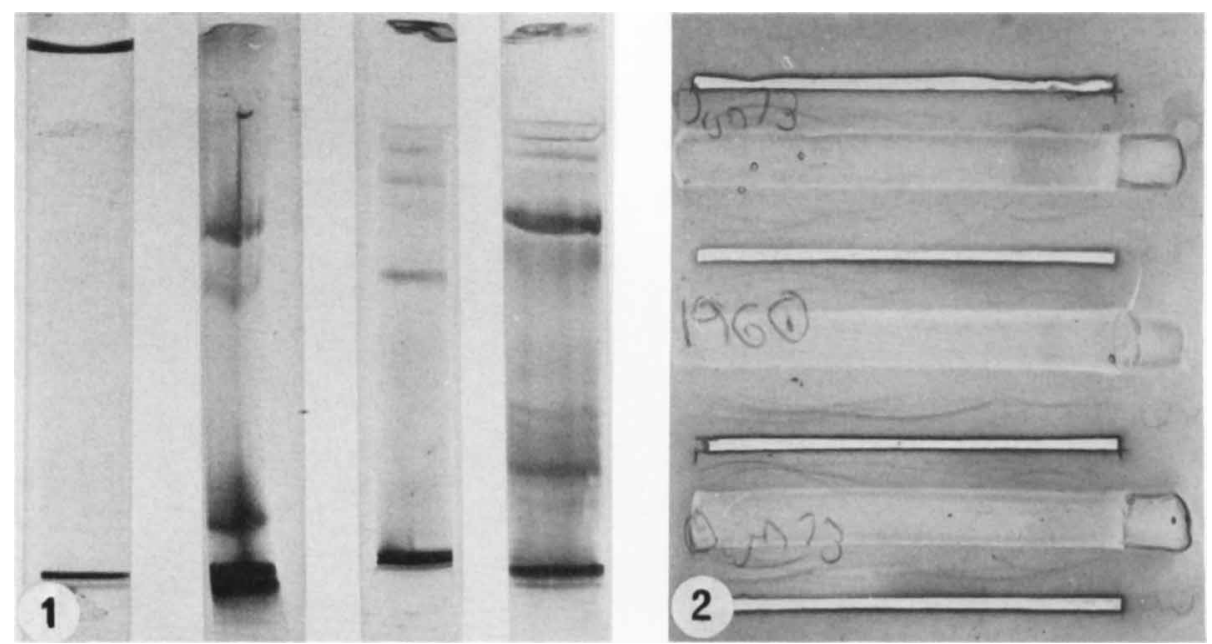

FIG. 1.-Polyacrylamide-gel electrophoresis (PAGE) of ammonium sulphate precipitated fractions from Aspergillus fumigatus, stained with Coomassie Blue. Left to right: fractions la, $2 \mathrm{a} ; 3 \mathrm{a}$, and 2 . Fraction 2 was equivalent to $3 \mathrm{a}$ but was obtained from a different batch of unfractionated water-soluble material.

Fig. 2.-PAGE-immunodiffusion of ammonium sulphate precipitated fractions tested against selected sera. Upper and lower gels, fraction 2; middle gel, fraction 1a. Troughs, top to bottom: homologous antiserum to unfractionated aqueous extract of $A$. fumigatus mycelium; antiserum to $A$. fumigatus culture filtrate; serum from patient with aspergilloma; pool of selected sera from patients with aspergiloma..
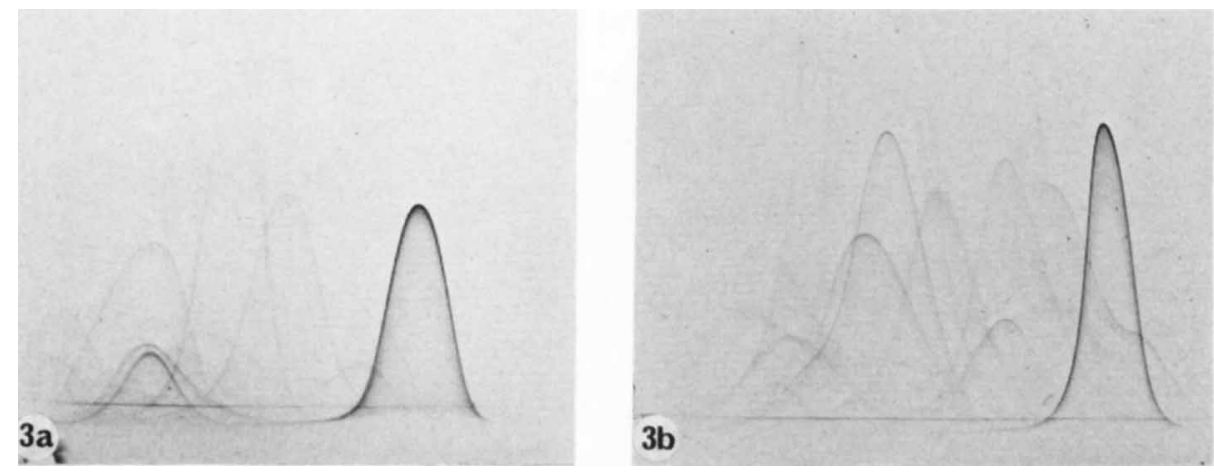

FIG. 3.-Fractions of control precipitate (CP) tested in two-dimensional immunoelectrophoresis against hyperimmune antiserum to culture-filtrate antigens. (a) CP fraction from batch I; (b) $\mathrm{CP}$ fraction from batch II. 

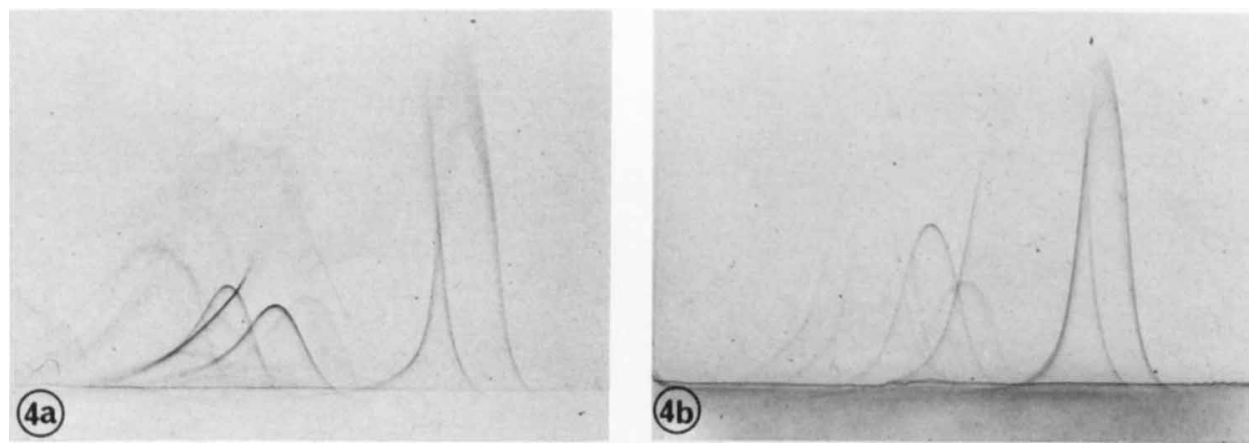

FIG. 4.-Ammonium sulphate fraction la from batch II tested against (a) a pool of selected sera of patients with aspergilloma and against (b) a pool of selected sera from patients with allergic bronchopulmonary aspergillosis.
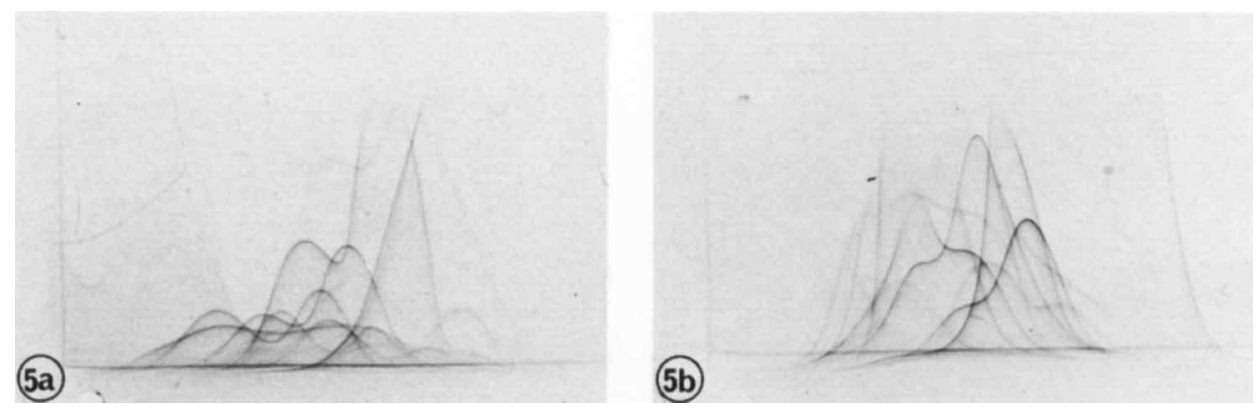

FIG. 5.-Tandem immunoelectrophoresis (IEP) of ammonium sulphate fractions from batch II tested against serum from a patient with aspergilloma. (a) tandem IEP of fractions la and $2 \mathrm{a}$ with $2 \mathrm{a}$ in the leading well; (b) tandem IEP of fractions $2 \mathrm{a}$ and $3 \mathrm{a}$ with $3 \mathrm{a}$ in the leading well. 


\section{ASPERGILLUS FUMIGATUS ANTIGENS}
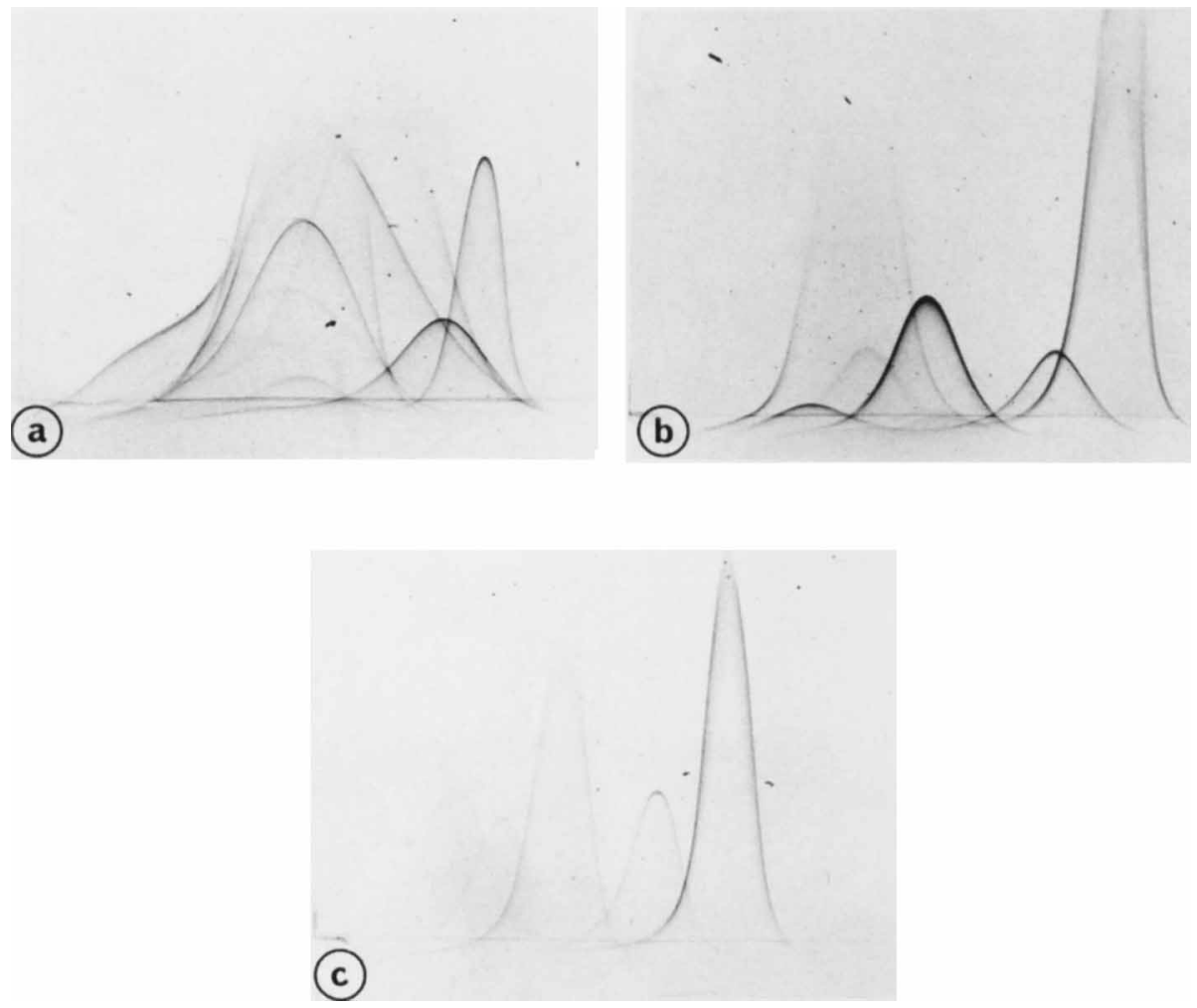

FIG. 6.-Ammonium sulphate fraction 1 from batch I tested against sera from three patients with aspergilloma. (a) Serum from patient no 1; (b) serum from patient no 2; (c) serum from patient no. 3 . 
ASPERGILLUS FUMIGATUS ANTIGENS
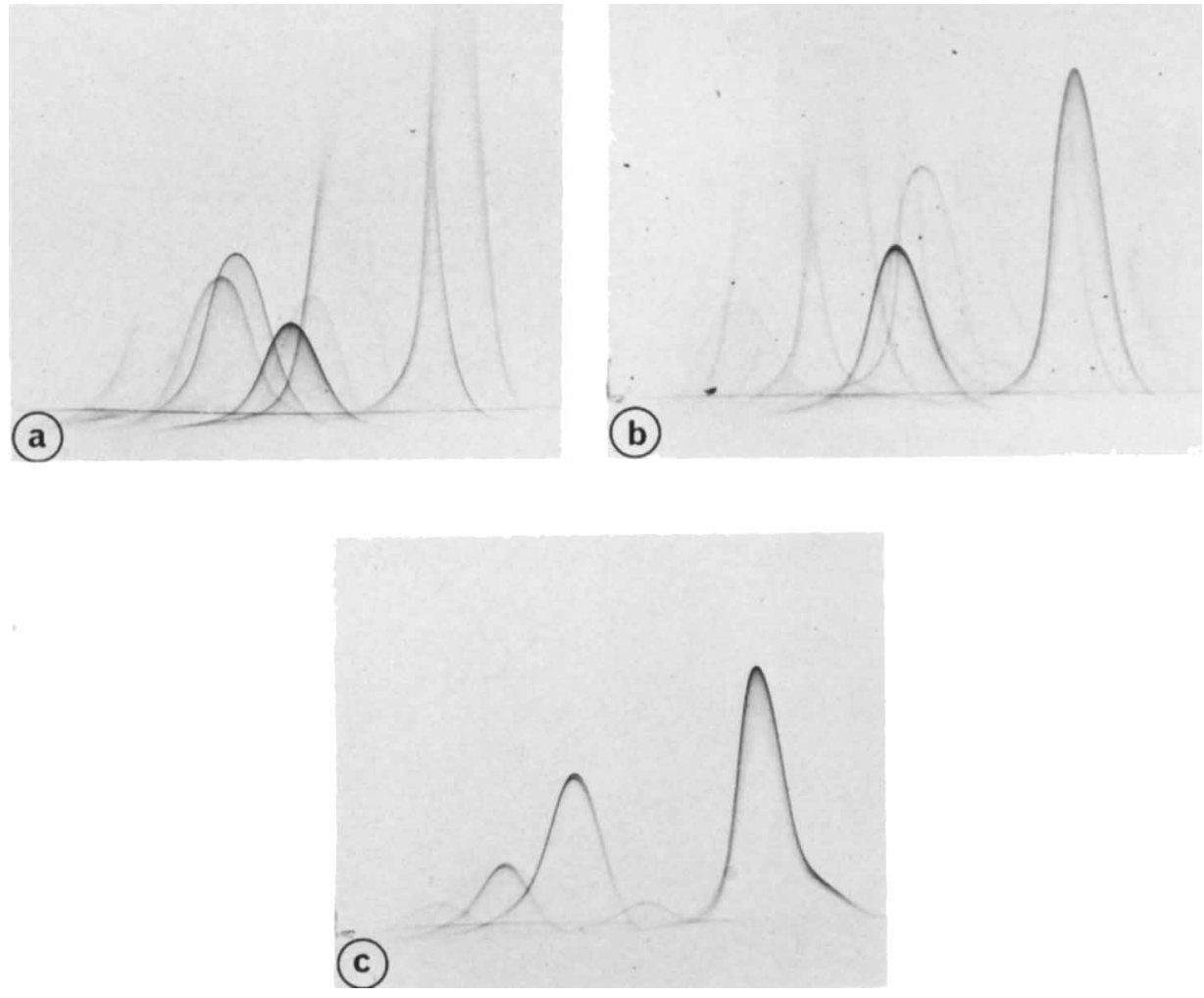

FIG. 7.-Ammonium sulphate fraction 2 from batch I tested against sera from three patients with aspergilloma. (a) Serum from patient no. 4; (b) serum from patient no. 2; (c), serum from patient no. 3 . 
tandem electrophoresis with an individual aspergilloma serum in the test. Each of the fractions was electrophoresed separately, showing 10-13 readily identifiable precipitin peaks. As may be seen from the tandem results, all the major components were shared by all three fractions (figs. 5a and 5b). This serum, from patient no. 2, was also tested against batch-I antigens (figs. $6 \mathrm{~b}$ and 7b).

\section{Serum-antibody variation}

Variation in the serum from individual patients was investigated with AS fractions 1 and 2 to the $50 \%$ saturation point. The results (figs. 6 and 7) showed a variation in the number and the intensity of the peaks. As few as three or as many as 12 components were found in the different serum samples in their reactions with the same antigenic fraction. When a serum was tested against both AS fractions, not all the precipitins were always detected with one fraction. When the same precipitation did occur, the peak height and intensity of staining often varied.

Effect of concanavalin A on immunoelectrophoresis profiles of ammonium sulphate fractions

Concanavalin A interacts specifically with carbohydrate structures of $\alpha$-Dmannopyranoside or $\alpha$-D-glucopyranoside configurations. Because these sugars are found in all $A$. fumigatus antigenic fractions under review, interaction with concanavalin A can be used for a partial structural characterisation of any glycoproteins present. The effect of concanavalin A on fraction 1 is seen in fig. 8. With concanavalin A incorporated in an intermediate gel, peak 1 was unaffected and peaks 4 and 5 were still faintly discernible (relative to the control) but peaks 2 and 3 were retained in the lower gel. A homologous antiserum was used in the test and comparable precipitates, present in fractions 1a and 2a, were similarly affected. Four additional poorly stained peaks with low profiles, which were present in fraction $2 \mathrm{a}$, were unaffected by concanava$\operatorname{lin} \mathrm{A}$.

\section{Discussion}

Multiple antigens are present in the ammonium sulphate precipitates from the aqueous extract of $A$. fumigatus mycelium (c.f., Kim et al., 1978). On fractionation, approximately $62 \%$ of the recovered material was found in the $0-50 \%$ AS-precipitate range. This contained the bulk of the protein, c. $90 \%$ of the total and $44.8 \%$ of the neutral polysaccharides. The results with sera from the 10 patients with aspergilloma showed that these fractions contained a wide spectrum of antigens which reacted with the IgG antibodies. The recurrence of certain antigen-antibody precipitates indicated a degree of common antigenicity and antibody response among the patients (c.f., Longbottom, 1978). Longbottom and Pepys (1964), after studies in which sera from a large number of patients were tested with culture-filtrate antigens, suggested that the use of 
several different extracts of $A$. fumigatus was necessary to obtain the greatest number of positive reactions; with the small number of samples that we used, though some test sera gave weak reactions with one or other of the antigenic fractions, this did not occur over the whole range of AS-precipitable fractions. In no instance was a negative result obtained when these antigens were tested against sera from patients with proven aspergilloma.

Above the $50 \%$ AS salt level, approximately two components possessing anodal mobility were seen with rabbit antisera; these were either undetectable or found in only trace amounts when human sera were used. Antigens found in the cathode area and which did not migrate in the second dimension were detected in the AS-soluble fraction against $33 \%$ of the sera analysed. They proved relatively insensitive in this test system, requiring $25 \mathrm{mg}$ carbohydrate/ml for visualisation. Kim et al (1978) described the reactivity of polysaccharide-enriched antigens in the AS-soluble fraction of their preparations. The fraction of the AS supernate with a protein : carbohydrate ratio of 0.08:1 gave two lines on double diffusion but no precipitation arcs on rocket electrophoresis. Also, Lehmann and Riess (1979) have shown the presence of a galactomannan antigen in alkali extracts of $A$. fumigatus mycelium which was

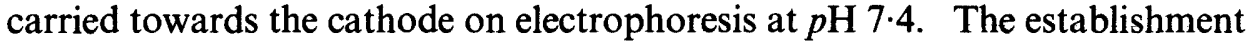
of any closer relationship among these antigens requires chemical analysis of the AS-soluble constituents.

When highly-concentrated ABPA specimens were examined they gave precipitation profiles very similar to those seen in cases of aspergilloma, with a similar distribution of antigen-antibody precipitates over the $0-50 \%$ AS concentration range. Thus it appears that circulating antibodies in allergic patients differ only in quantity from those found in aspergilloma.

Subfractionation of the $0-50 \%$ AS precipitates into three showed many well defined precipitation peaks distributed over the whole range when they were tested against a strongly reactive antiserum. By tandem electrophoresis, shared antigenic components were found in all three fractions. Thus by salt precipitation alone it is not possible to distinguish between immunologically identical antigens. However, these subfractions, with a smaller number of components, could be more suitable for analytical studies, e.g., partial structural characterisation by affinity binding to lectins, as demonstrated here. It is of interest that fraction $1 \mathrm{a}$, which constitutes only $17 \%$ of the yield and is predominantly carbohydrate, reacted strongly with rabbit and with human antisera. Here the bulk of the activity was lost through interaction with concanavalin $\mathrm{A}$, with the notable exception of peak 1 and reduced intensity of peaks 4 and 5 .

The AS fractions of two preparations of $A$. fumigatus were compared for batch-to-batch variability. Their PAGE patterns were examined by staining with Coomassie Blue (fig. 1) and their precipitation profiles were analysed with an antiserum to culture-filtrate antigens (fig. 3). Distinct differences were visible and antigenic reproducibility remains a problem.

Salt fractionation of $\boldsymbol{A}$. fumigatus water-soluble extracts is a useful tool for chemical and immunological studies of $A$. fumigatus precipitating antigens 
ASPERGILLUS FUMIGATUS ANTIGENS

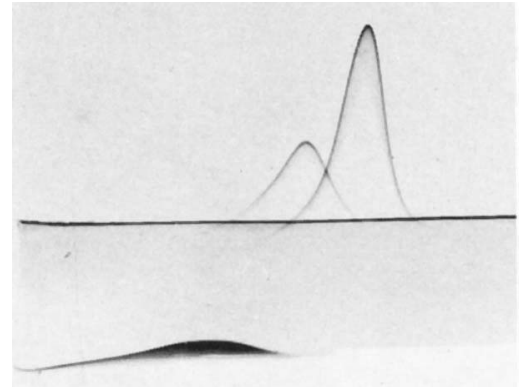

(a)

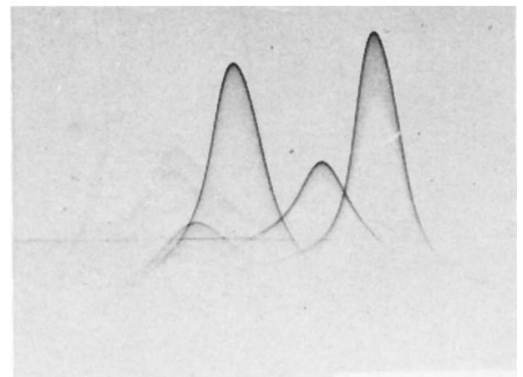

(b)

FIG. 8.- Intermediate-gel immunoelectrophoresis with AS fraction 1 of batch I against a homologous antiserum. (a) Concanavalin $\mathrm{A}$ in the intermediate gel; (b) control without lectin in the intermediate gel. 
with special reference to the patient's antibody response. The method provides a simple, relatively mild procedure in which, by use of the $0-50 \%$ AS-precipitable fraction, approximately $55 \%$ of the total neutral carbohydrate may be eliminated with little loss of precipitability. Carbohydrate-enriched material, found in the AS-soluble fraction, has been shown to contain some precipitable antigens. It is also known that this fraction contains antigens that will bind antibodies without concomitant precipitation (Bardana et al., 1972). An AS-soluble fraction from a culture-filtrate preparation has been used by Sepulveda, Longbottom and Pepys (1979) in ELISA tests, from which they report a higher level of antibodies to this fraction in the sera of ABPA patients than in aspergilloma patients' sera. Thus, this one-step fractionation procedure could provide a potentially useful separation of $A$. fumigatus mycelial antigens for the measurement of different immunological characteristics.

\section{SUMMARY}

The water-soluble components of Aspergillus fumigatus mycelium were partially separated by fractional precipitation with ammonium sulphate. The total protein and neutral-sugar content were determined for each of the four fractions prepared and their immunological activity was examined by double diffusion. Partial chemical characterisation of these isolates by polyacrylamide-gel electrophoresis was linked to their precipitability by allowing the separated components to diffuse from the gel into an agarose medium containing an appropriate antiserum. The distribution and reactivity of antigens was monitored by two-dimensional immunoelectrophoresis with rabbit sera raised against either mycelial or culture-filtrate antigens and human sera, obtained from patients with aspergilloma and from patients with allergic bronchopulmonary aspergillosis. This technique was also used to establish that considerable variation exists in the precipitation profile seen among patient specimens. Several antigens were found to possess sugar residues that interacted with concanavalin $\mathrm{A}$, when this lectin was used in an intermediate gel in two-dimensional immunoelectrophoresis.

This work was supported by a grant from the Medical Research Council.

\section{REFERENCES}

Azuma, I., Kimura, H., Hirao, F., Tsubura, E. and Yamamura, Y. 1967. Skin-testing and precipitation antigens from Aspergillus fumigatus for diagnosis of aspergillosis. Am. Rev. resp. Dis., 95, 305.

Bardana, E. J., McClatchy, J. K., FarR, R. S. AND Minden, P. 1972. The primary interaction of antibody to components of aspergilli. I. Immunologic and chemical characteristics of a nonprecipitating antigen. J. Allergy clin. Immunol., 50, 208.

Bøg-Hansen, T. C., Brogren, C.-H. AND MCMurRough, I. 1974. Identification of enzymes as glycoproteins containing glucose or mannose. Interaction of barley malt proteins with concanavalin A in electrophoresis. J. Inst. Brew., 80, 443.

Dubois, M., Gilles, K. A., Hamilton, J. K., Rebers, P. A. and Smith, F. 1956. Colorimetric method for determination of sugars and related substances. Analyt. Chem., 28, 350. 
Fletcher, S. M., Rondle, C. J. M. And Murray, I. G. 1970. The extracellular antigens of Micropolyspora faeni: their significance in farmer's lung disease. J. Hyg., Camb., 68, 401.

HEARN, V. M. AND MACKenZIE, D. W. R. 1979. The preparation and chemical composition of fractions from Aspergillus fumigatus wall and protoplasts possessing antigenic activity. J. gen. Microbiol., 112, 35.

Kim, S. J. AND ChaPARAS, S. D. 1978. Characterization of antigens from Aspergillus fumigatus. I. Preparation of antigens from organisms grown in completely synthetic medium. Am. Rev. resp. Dis., 118, 547.

Kim, S. J., Chaparas, S. D., Brown, T. M. And Anderson, M. C. 1978. Characterization of antigens from Aspergillus fumigatus. II. Fractionation and electrophoretic, immunologic and biologic activity. Am. Rev. resp. Dis., 118, 553.

LehmanN, P. F. AND ReISs, E. 1979. Aspergillus fumigatus antigenaemia: detection of antigen in mice and in human patients. Bull. Soc. mycol. Med., 8, 57.

LONGBOTTOM, J. L. 1978. Immunological aspects of infection and allergy due to Aspergillus species. Mykosen, suppl. 1, 207.

LONGBOtTom, J. L. AND PEPYS, J. 1964. Pulmonary aspergillosis: diagnostic and immunological significance of antigens and c-substance in Aspergillus fumigatus. J. Path. Bact., 88, 141.

LONGBOTtOM, J. L. 1978. Immunological aspects of infection and allergy due to Aspergillus species. Mykosen, suppl. 1, 207.

Lowry, O. H., Rosebrough, N. J., Farr, A. L. and Randall, R. J. 1951. Protein measurement with the Folin phenol reagent. J. biol. Chem., 193, 265.

Lund, B. M. 1965. A comparison by the use of gel electrophoresis of soluble protein components and esterase enzymes of some group D streptococci. J. gen. Microbiol., 40, 413.

Pappagianis, D., Smith, C. E., Kobayashi, G. S. and SaIto, M. T. 1961. Studies of antigens from young mycelia of Coccidioides immitis. J. infect. Dis., 108, 35.

Proctor, A. G. 1976. Mycological methods. In Microbiological methods, 4th ed., edited by C. H. Collins and P. M. Lyne. Butterworth: London, p. 181.

SePulveda, R., Longbotrom, J. L. AND PePYs, J. 1979. Enzyme-linked immunosorbent assay (ELISA) for IgG and IgE antibodies to protein and polysaccharide antigens of Aspergillus fumigatus. Clin. Allergy, 9, 359.

SteinduCH, M. AND Audran, R. 1969. The isolation of IgG from mammalian sera with the aid of caprylic acid. Archs Biochem. Biophys., 134, 279.

Tran van Ky, P., Biguet, J. and Vaucelle, T. 1968. Etude d'une fraction antigénique d'Aspergillus fumigatus support d'une activité catalasique. Conséquence sur le diagnostic immunologique de l'aspergillose. Rèv. d'Immunol., Paris, 32, 37.

WADA, I. 1960. Immunological studies on aspergillosis. I. Immunological reactions in experimental aspergillosis by the filtrate from ground mycelia of Aspergillus fumigatus. Jap. J. Bact., 15, 528 (in Japanese). 